\title{
Age-related changes in mitochondrial UCP, ANT and COX III gene expression in the breast muscle of quails (Coturnix coturnix japonica)
}

\author{
E. Gasparino ${ }^{1}$, A.P. Del Vesco ${ }^{1}$, S.E.F. Guimarães ${ }^{2}$, S.C.C. da Silva ${ }^{1}$, \\ S.M. Marcato ${ }^{1}$, A.R. de Oliveira Neto $^{3}$ and K.R.S. Sousa ${ }^{2}$ \\ ${ }^{1}$ Departamento de Zootecnia, Universidade Estadual de Maringá, \\ Maringá, PR, Brasil \\ ${ }^{2}$ Departamento de Zootecnia, Universidade Federal de Viçosa, \\ Viçosa, MG, Brasil \\ ${ }^{3}$ Evonik Degussa, São Paulo, SP, Brasil \\ Corresponding author: A.P. Del Vesco \\ E-mail: apaulavesco@gmail.com
}

Genet. Mol. Res. 11 (3): 1981-1989 (2012)

Received July 4, 2011

Accepted December 22, 2011

Published August 6, 2012

DOI http://dx.doi.org/10.4238/2012.August.6.2

\begin{abstract}
Efficient conversion of food into body mass has been associated with altered gene expression of some proteins of the electron transport chain. We evaluated the effect of age on mRNA expression of uncoupling protein, adenine nucleotide translocase and cytochrome $\mathrm{c}$ oxidase complex III in quails. One-day-old broiler quails were sacrificed after $7,14,21$, or 28 days. Six quails of each age were slaughtered by cervical dislocation. Total RNA was extracted from the breast muscle and reverse transcribed into cDNA. Real-time PCR analysis was performed using specific primers for the genes. As the quails aged, there was reduced expression of all three genes. The greatest reduction when comparing 7- and 28-day-old birds was observed in the uncoupling protein mRNA levels $(67 \%)$, followed by adenine nucleotide translocase $(56 \%)$ and cytochrome c oxidase complex III $(30 \%)$. We conclude that expression of some mitochondrial genes of the
\end{abstract}


electron transport chain changes with age in quails.

Key words: Oxidative damage; Aging; Mitochondria; UCP; ANT; COX III

\section{INTRODUCTION}

Genetic improvement has greatly enhanced the performance of poultry in recent years, for instance by drastically reducing the slaughter age. Recent studies have shown that animals that convert food into body mass more efficiently can display alterations in the electron transport chain gene expression, which can influence the use of nutrients and alter body energy consumption. Such research suggests that animals with a higher residual feed intake may suffer failure in the transport of electrons/protons, thus reducing the efficiency of ATP production by the mitochondrial genes, which has an adverse effect on feed conversion (Johnson et al., 2003; Iqbal et al., 2005; Krueger et al., 2008; Bottje and Carstens, 2009). The loss of efficiency in nutrient use with age may be related to such failure.

All cells need energy to perform their activities. Mitochondria are the organelles responsible for transforming chemical energy from metabolites into energy easily accessed by the cell (Schauss et al., 2010). This energy is accumulated in labile compounds, the main one being ATP. It is known that with age the process of energy production is gradually impaired, partly due to the build up of free radicals during ATP production and also by increased mtDNA lesions.

Regarding the free-radical process of aging, Harman's theory suggests that the formation of free radicals inside the cells during energy generation is harmful to cell functioning. According to this theory, typical indications of aging are: increased suppression/mutation in mtDNA, overproduction of reative oxygen species (ROS), and increased mitochondrial dysfunction as well (Nicoletti et al., 2005). Oxidative damage and impaired efficiency of the respiratory chain of mitochondria related to aging seem to involve a vicious cycle where mtDNA lesions may affect respiratory chain functioning, such as electron escape, which could lead to higher quantities of ROS and result in more mtDNA lesions (Tengan et al., 1998).

Increased production of mitochondrial ROS, which occurs with advancing age is related to greater oxidative damage in the macromolecules, as well as depletion in the energy production machinery. Birds with lower ATP production due to lower mitochondrial efficiency in producing ATP from substrates show worse efficiency or feed conversion. Therefore, mechanisms that favor a reduced ROS production may be useful in the prevention of age-related issues.

Various studies have been conducted with the aim of relating the biochemical functions of mitochondria, such as ROS production and expression of proteins of the respiratory chain complexes involved in metabolism, with the feed efficiency of animals (Barazzoni et al., 2000; Kerner et al., 2001; Rebrin et al., 2005; Zhang et al., 2010). It is known that free radicals, which tend to accumulate during aging, could be related to gene expression of mitochondria involved in metabolic energy conversion, thus affecting the performance of the birds (Ojano-Dirain et al., 2007). Therefore, the aim of this study was to evaluate the effect of aging on the mRNA expression of three mitochondrial genes related to energy production and ATP synthesis, where the genes uncoupling protein (UCP), adenine nucleotide translocase (ANT) and cytochrome c oxidase III (COX III) were analyzed in quails at 7, 14, 21, and 28 days of age. 


\section{MATERIAL AND METHODS}

This study was conducted at the Poultry Farm of the State University of Maringá, and at the molecular genetics laboratory of the Animal Science Department of the Federal University of Viçosa.

One hundred and forty-four 1-day-old broiler quails were used, which were randomly distributed into four age groups (7, 14, 21, and 28 days old). At the end of each age period, six birds from each group were slaughtered based on the average weight. The animals were kept in a conventional warehouse, in $2.5-\mathrm{m}^{2}$ compartments, which were lined with rice husk bedding. A continuous illumination scheme was adopted during all the experimental period.

Corn and soybean meal-based animal feed was used, in accordance with the nutritional recommendations of Rostagno et al. (2005) and NRC (1994) (Table 1).

\begin{tabular}{lc}
\multicolumn{1}{c}{ Table 1. Animal feed composition. } \\
\hline Ingredient & Percent \\
\hline Soybean meal & 50.59 \\
Corn & 40.24 \\
Soybean oil & 4.84 \\
Glycerol & 0.00 \\
Dicalcium phosphate & 1.55 \\
DL-methionine & 0.65 \\
L-lysine & 0.65 \\
L-threonine & 0.35 \\
Salt & 0.40 \\
Limestone & 0.36 \\
Premix & 0.35 \\
Calculated composition (\%) & \\
Crude protein & 27.52 \\
Lysine & 1.88 \\
Met+Cys & 1.44 \\
Threonine & 1.22 \\
Tryptophan & 0.30 \\
Sodium & 0.18 \\
Calcium & 0.65 \\
Available phosphorus & 0.41 \\
Apparent metabolizable energy (kcal/kg) & 3000 \\
\hline
\end{tabular}

The quails were weighed at the end of each experimental period of 7, 14, 21, and 28 days, in order to ascertain body weight gain. The animal feed served and the leftovers were weighed to calculate consumption. The feed conversion ratio was calculated, between weight gain and feed consumption. Mortality was considered for the feed conversion calculation. Six quails from each treatment group were killed by cervical dislocation at the end of each age period. A sample of the breast muscle (pectoralis superficialis) of these birds was collected, suitably conditioned in RNA Holder ${ }^{\circledR}$ (BioAgency) and stored at $-20^{\circ} \mathrm{C}$ until RNA extraction.

Total RNA was extracted using the Trizol ${ }^{\circledR}$ reagent (Invitrogen, Carlsbad, CA, USA) at a concentration of $1 \mathrm{~mL}$ for every $100 \mathrm{mg}$ tissue. The muscle tissue was ground with an electric homogenizer until complete dissociation. Subsequently, $200 \mu \mathrm{L}$ chloroform was added and the tissue manually homogenized for $1 \mathrm{~min}$. The resulting homogenate was centrifuged for $15 \mathrm{~min}$ at $12,000 \mathrm{rpm}$ at $4^{\circ} \mathrm{C}$, and the liquid phase was collected and transferred to a test tube, where $500 \mu \mathrm{L}$ isopropanol was added. Next, the material was homogenized, centrifuged for $15 \mathrm{~min}$ at $12,000 \mathrm{rpm}$ and $4^{\circ} \mathrm{C}$. The supernatant material was discarded and the precipitate was washed with $1 \mathrm{~mL} \mathrm{75 \%}$ ethanol. The material was then centrifuged again at 12,000 rpm for 5 
min, and the supernatant discarded. The precipitate was air-dried for $15 \mathrm{~min}$ and homogenized in distilled and deionized, RNase-free water.

Total RNA concentration was determined with a spectrophotometer, at a wavelength of $260 \mathrm{~nm}$. RNA integrity was assessed on a 1\% agarose gel and visualized under ultraviolet light (data not shown).

cDNA was prepared using a SuperScript ${ }^{\mathrm{TM}}$ III First-Strand Synthesis Super Mix kit (Invitrogen Corporation, Brazil). Six microliters of total RNA, $1 \mu \mathrm{L}$ oligo (dT) $\left(50 \mu \mathrm{M}\right.$ oligo(dT) ${ }_{20}$ and $1 \mu \mathrm{L}$ annealing buffer were added. The reaction mixture was incubated for $5 \mathrm{~min}$ at $65^{\circ} \mathrm{C}$ and then placed on the gel for $1 \mathrm{~min}$. Subsequently, $10 \mu \mathrm{L} 2 \mathrm{X}$ First-Strand Reaction Mix solution and 2 $\mu \mathrm{L}$ a solution containing the enzyme SuperScript III reverse transcriptase and RNase inhibitor were added. The solution was incubated for $50 \mathrm{~min}$ at $50^{\circ} \mathrm{C}$ for synthesis of the complementary DNA. The reaction mixture was then incubated again for $5 \mathrm{~min}$ at $85^{\circ} \mathrm{C}$ and then immediately placed on ice. The samples were stored at $-20^{\circ} \mathrm{C}$ until the time of the subsequent analyses.

The primers of the genes COXIII (NP_006921), avANT (AB088686) and avUCP (AB088685) were obtained from Ojano-Dirain et al. (2007). These sequences can be obtained at the website www.ncbi.nlm.nih.gov. The primers for $\beta$-actin (endogenous control) were designed according to the sequence deposited in GenBank (accession No. L08165), using the website www.idtdna.com.

Two endogenous controls were tested, the $\beta$-actin and GAPDH genes, with the $\beta$-actin gene used due to a better efficiency in the reaction and lower variation across treatments. All the trials were performed in a final volume of $25 \mu \mathrm{L}$ and in duplicate. SYBR GREEN (SYBR ${ }^{\circledR}$ GREEN PCR Master Mix (Applied Biosystems, USA) fluorescent compound was used for real-time PCR.

The data were analyzed using the SAS GLM procedure (2000). The averages were analyzed by the Tukey test $(\mathrm{P}<0.05)$. The normality of gene expression residues (expressed with $2^{-\Delta \mathrm{Ct}}$ ) and production data were verified using the UNIVARIATE procedure. Logarithmic transformation $[\ln (x+1)]($ Voge et al. 2004) was applied to all the genes evaluated due to their failure to meet the assumptions of normality.

\section{RESULTS}

The primers for the ANT, COX III, and UCP genes proved in this study to be adequate for real-time PCR analysis. The analysis of the dissociation curves did not reveal any presence of unspecific products or the formation of primer dimers, demonstrating the reliability of the data in determining mRNA expression of the genes evaluated. $\beta$-actin used as the endogenous control did not show any statistically significant difference across the ages studied. This proves the efficiency of its use as the endogenous control (Table 2).

Table 2. Expression of the $\beta$-actin gene at different ages, by the real-time PCR technique.

\begin{tabular}{lccc}
\hline Age (days) & & Endogenous control $\beta$-actin. & UCP \\
\cline { 2 - 4 } & avANT & COX III & $28.85 \pm 0.85$ \\
\hline 7 & $28.41 \pm 0.86$ & $28.62 \pm 1.22$ & $29.12 \pm 0.42$ \\
14 & $29.66 \pm 1.62$ & $28.77 \pm 0.59$ & $28.92 \pm 1$ \\
21 & $28.67 \pm 0.75$ & $28.45 \pm 0.74$ & $28.96 \pm 0.31$ \\
28 & $28.43 \pm 0.42$ & $28.39 \pm 0.42$ & 2.44 \\
Coefficient of variation (\%) & 3.52 & 2.81 & 2.44
\end{tabular}

Mean and standard deviation of the CT values obtained in the samples of muscle tissue for analysis of the expressions of UCP, COX III and avANT. 
Figure 1 shows ANT, COX III and UCP gene expressions in the breast muscle of quails aged 7, 14, 21, and 28 days. As the animals aged, there was a reduction in all gene expressions analyzed. ANT mRNA expression was reduced by $30 \%$ at 14 days, $35 \%$ at 21 days and $56 \%$ at 28 days, when compared to ANT mRNA expression in 7-day-old birds. In relation to COX III mRNA expression in the birds' skeletal muscle, a 39\% drop was observed at 14 days, $49 \%$ at 21 days and $30 \%$ at 28 days, compared to the corresponding expression in 7-day-old birds. However, 21-day-old birds showed an increase in expression in relation to 28-day-old birds (4.46 vs 6.11). There was also a reduction in UCP mRNA expression of 39, 54 and $67 \%$ at 14,21 and 28 days, respectively, compared to 7 days.
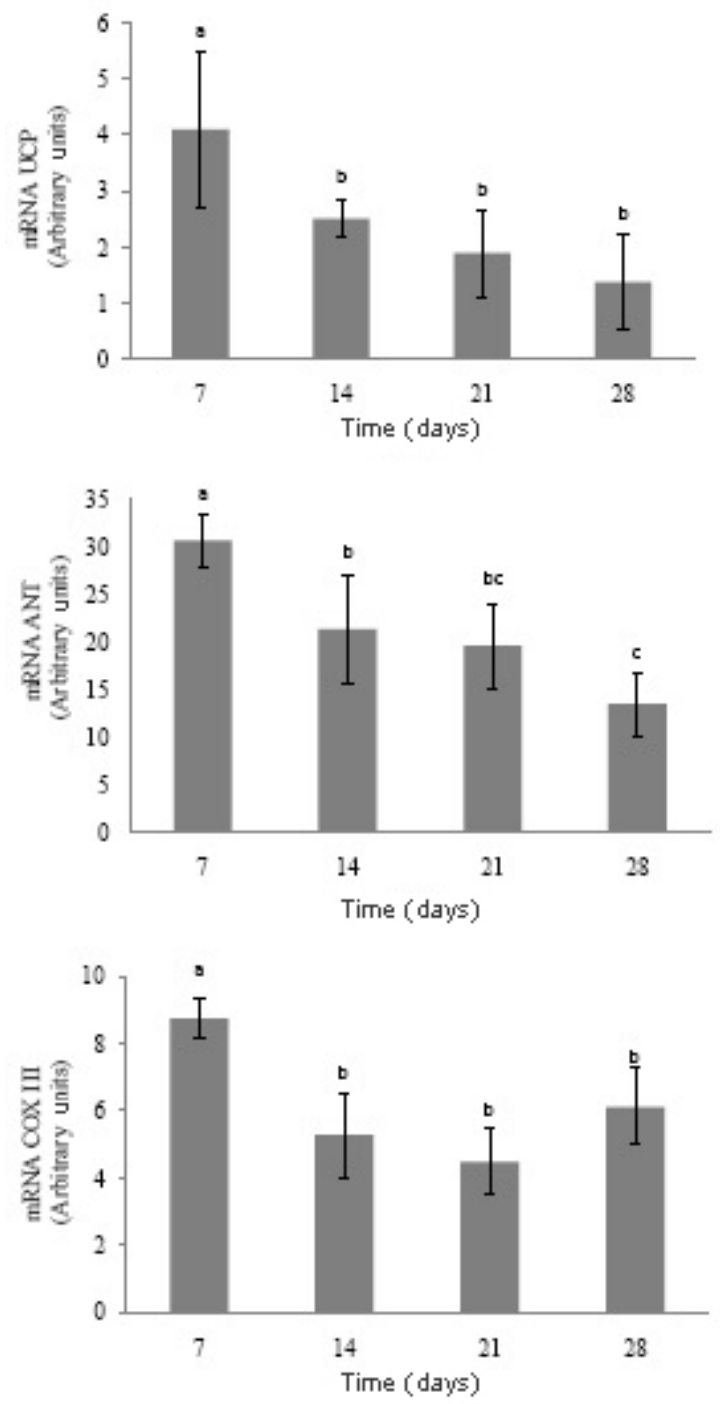

Figure 1. mRNA expression of nucleotide translocase (ANT), cytochrome oxidase complex III (COX III), and uncoupling protein (UCP) in the skeletal muscle of quails at 7, 14, 21, and 28 days of age. 
The body mass gain and feed conversion are presented in Table 3 .

Table 3. Weight gain and feed conversion of the birds during the different age periods.

\begin{tabular}{ccc}
\hline Age (days) & Weight gain $(\mathrm{g})$ & Feed conversion $(\mathrm{kg} / \mathrm{kg})$ \\
\hline $1-7$ & 25.170 & 1.40 \\
$8-14$ & 44.23 & 1.72 \\
$15-21$ & 50.10 & 2.40 \\
$22-28$ & 56.68 & 2.62 \\
\hline
\end{tabular}

\section{DISCUSSION}

It is common knowledge that the feed conversion efficiency of birds is impaired by aging. This efficiency may be related to the process of energy production by the cells. Recent studies have shown that animals with a lower energy production due to lower ATP production efficiency of the mitochondria show worse feed conversion (Parker et al., 2008; Bottje et al., 2009). Mitochondrial dysfunction can occur as a result of ROS accumulation or mtDNA damage, as well as the combined action of both; the occurrence of these factors can be increased by aging.

According to the chemiosmotic hypothesis, free energy generated by electron transport when moving through the respiratory chain until reaching the final electron acceptor, $\mathrm{O}_{2}$, is used to produce ATP from ADP+Pi. The mitochondrial enzymes involved in oxidative phosphorylation are positioned in the inner membrane of the organelle, and arranged in five multiprotein complexes: NADH:ubiquinone reductase (complex I); succinate:ubiquinone reductase (complex II); ubiquinol:cytochrome c reductase (complex III); ferrocytochrome c:oxygen oxidoreductase (complex IV), and ATP synthase (complex V) (Lehninger et al., 1993). During ATP synthesis, approximately 2 to $4 \%$ of the total $\mathrm{O}_{2}$ used as the electron acceptor by the mitochondria is not completely reduced to water (Bottje et al., 2006); however, this portion forms the chemical compounds that are still powerful oxidants, known as ROS. These substances are capable of oxidizing biological macromolecules such as proteins. Studies on protein oxidation by $\mathrm{O}_{2}$ have shown that it can selectively oxidize amino acid residues or protein aggregates, leading to their destruction. Moreover, protein peroxides can react with other biomolecules, such as DNA, generating additional damage (Ronsein et al., 2006).

ROS production by cells occurs normally during ATP production; however, with advancing age, this production increases. A vicious cycle seems to run in this process. The escape of electrons due to disturbances in the respiratory chain increases the production of free radicals, which in turn causes more lesions in mtDNA, resulting in additional production of ROS (Tengan et al., 1998).

It is suggested that, with age, more failures in ATP production occur due to the impaired activity of the respiratory chain complexes (Ferrandiz et al., 1994). In the present study, the older birds showed lower expression of all the mitochondrial genes analyzed - UCP, ANT, and COX III - combined with reduced productive efficiency, such as impaired feed conversion (Table 3). It is possible that accumulation of cellular ROS and subsequent damage to mtDNA are partly responsible for these results.

The greatest alteration in gene expression due to aging was observed in UCP expression. The UCPs are transporters in the inner mitochondrial membrane, which divert ATP synthesis energy to heat production, catalyzed by a leak of protons through the inner 
membrane (Ledesma et al., 2002). UCPs provide a new route for the protons, rather than through ATP synthase (Vidal-Puig, 2000). avUCP has been described as an agent that enables a reduction in ROS production by causing a slight uncoupling in ATP production (Abe et al., 2006). Although UCPs have the beneficial effect of preventing damage to DNA and cellular proteins, as they reduce the production of free radicals, it has been observed that a greater UCP mRNA expression can impair feed conversion, as it can reduce ATP production (Ojano-Diran et al., 2007). Diminished ATP synthesis can lead to increased catabolism of the nutrients as a means of maintaining energy production. We observed a gradual reduction in UCP mRNA as the quails aged. Quails of 28 days showed a $67 \%$ lower UCP mRNA expression than the 7-day-old quails. This reduction was accompanied by increased body mass gain, but the birds became less efficient in their use of nutrients (Table 3).

Studies show that mitochondrial proteins are reduced with age (Beyer et al., 1984; Kerner et al., 2001). A lower UCP mRNA expression has been observed in the skeletal muscle of older rats (Barazzoni and Nair, 2001; Iritani et al., 2002). A 68\% decrease in the UCP 3 protein in rats aged 24 months compared to 6-month-old rats was observed by Kerner et al. (2001). According to the author, considering the role played by UCP in the metabolic rate and the metabolism of lipids, its reduced expression in the skeletal muscle may be associated with greater weight gain with the advance of age; however, no difference was found in weight gain of the rats between the two ages.

Another protein involved in energy synthesis is ANT (ADP/ATP translocase), responsible for moving ADP from the cytosol to the mitochondria and for moving ATP through the inner mitochondrial membrane (Ojano-Dirain et al., 2007). Therefore, ANT has the function of increasing the quantity of ADP to be transformed into ATP by means of ATP synthase. The mitochondrial function may be impaired by the incapacity of ADP/ATP exchange between the cytosol and the membrane, thus there may be some connection between the ANT expression with the phenotypic expression of feed efficiency (Bottje et al., 2006). In the present study, we found that older birds displayed a lower ANT mRNA expression in muscle tissue, and poorer feed conversion, just as Ojano-Dirain et al. (2007) also reported that birds with a lower ANT expression had a worse feed efficiency due to the lower ATP production efficiency. Nicoletti et al. (2005) also found a reduced ANT expression correlated to aging. According to these authors, alterations in the expression of respiratory chain subunits may represent an adaptive cellular response to the accumulated damage to proteins and/or mitochondrial DNA that occurs due to the increased quantity of ROS. However, such mechanism would not seem to be so efficient in animals of more advanced age. Coordination between respiratory chain complexes, which is necessary for efficient energy production and therefore for animals with greater feed efficiency, requires balanced activities and quantities between the complexes. Any imbalance may cause an electron leak and ROS generation.

COX III is also present in the electron transport chain and related to oxidative phosphorylation efficiency. COX III is a subunit of protein complex IV of the mitochondria, responsible for pumping protons and transporting electrons. COX III plays an important role in mitochondrial energy efficiency (Scheffler, 1999), and a lower expression of this gene can occur due to lower cellular efficiency or greater oxidative damage due to the production of ROS (Kemp et al., 2003). Ojano-Dirain et al. (2007) suggest that a greater ROS production and greater protein oxidation are consistently found in birds with lower feed efficiency, indicating that this factor may alter the expression of mitochondrial genes. Greater production of free 
radicals and greater protein oxidation are also related to aging (Nicoletti et al., 2005). Barazzoni et al. (2000) verified a reduction in COX III mRNA expression related to altered oxidative capacity of mitochondria in older animals. In our study, we found a reduced expression of COX III mRNA in quails aged 14, 21 and 28 days when compared to the 7-day-old birds. The alteration of this gene expression was accompanied by an impaired feed efficiency of the quails. This would indicate that maintaining transcription levels may be essential to mitochondrial oxidative capacity and the maintenance of efficient use of nutrients.

Further research is necessary to better understand the effect of mitochondrial gene expression on quail feed efficiency.

\section{CONCLUSION}

In this study, aging influenced the expression of all genes analyzed, showing that the age of birds does influence the expression of electron transport chain genes, responsible for body energy production.

\section{ACKNOWLEDGMENTS}

The authors are grateful to Procad-CAPES and CNPq.

\section{REFERENCES}

Abe T, Mujahid A, Sato K, Akiba Y, et al. (2006). Possible role of avian uncoupling protein in down-regulating mitochondrial superoxide production in skeletal muscle of fasted chickens. FEBS Lett. 580: 4815-4822.

Barazzoni R and Nair KS (2001). Changes in uncoupling protein-2 and -3 expression in aging rat skeletal muscle, liver, and heart. Am. J. Physiol. Endocrinol. Metab. 280: E413-419.

Barazzoni R, Short KR and Nair KS (2000). Effects of aging on mitochondrial DNA copy number and cytochrome c oxidase gene expression in rat skeletal muscle, liver, and heart. J. Biol. Chem. 275: 3343-3347.

Beyer RE, Starnes JW, Edington DW, Lipton RJ, et al. (1984). Exercise-induced reversal of age-related declines of oxidative reactions, mitochondrial yield, and flavins in skeletal muscle of the rat. Mech. Ageing Dev. 24: 309-323.

Bottje W and Carstens GE (2009). Association of mitochondrial function and feed efficiency in poultry and livestock species. J. Anim. Sci. 87: E48-E63.

Bottje W, Pumford NR, Ojano-Dirain C, Iqbal M, et al. (2006). Feed Efficiency and Mitochondrial Function. Poult. Sci. 85: 8-14.

Bottje W, Brand MD, Ojano-Dirain C, Lassiter K, et al. (2009). Mitochondrial proton leak kinetics and relationship with feed efficiency within a single genetic line of male broilers. Poult. Sci. 88: 1683-1693.

Ferrandiz ML, Martinez M, De Juan E, Diez A, et al. (1994). Impairment of mitochondrial oxidative phosphorylation in the brain of aged mice. Brain. Res. 644: 335-338.

Iqbal M, Pumford NR, Tang ZX, Lassiter K, et al. (2005). Compromised liver mitochondrial function and complex activity in low feed efficient broilers are associated with higher oxidative stress and differential protein expression. Poult. Sci. 84: 933-941.

Iritani N, Sugimoto T, Fukuda H and Kimura T (2002). Changes in UCP family expressions in rat tissues due to diet and aging. J. Nutr. Sci. Vitaminol. 48: 410-416.

Johnson DE, Ferrel CL and Jenkin TG (2003). The history of energetic efficiency research: Where have we been and where are we going? J. Anim. Sci. 81: E27-E38.

Kemp TJ, Causton HC and Clerk A (2003). Changes in gene expression induced by $\mathrm{H}_{2} \mathrm{O}_{2}$ in cardiac myocytes. Biochem. Biophys. Res. Commun. 307: 416-421.

Kerner J, Turkaly PJ, Minkler PE and Hoppel CL (2001). Aging skeletal muscle mitochondria in the rat: decreased uncoupling protein-3 content. Am. J. Physiol. Endocrinol. Metab. 281: E1054-E1062.

Krueger WK, Carstens GE, Lancaster PA and Slay LJ (2008). Relationship between residual feed intake and apparent 
nutrient digestibility in growing calves. J. Anim. Sci. 86: 25 .

Ledesma A, de Lacoba MG and Rial E (2002). The mitochondrial uncoupling proteins. Genome Biol. 3: S3015.

Lehninger AL, Nelson DL and Cox MM (1993). Principles of Biochemistry. 2nd edn. Worth Publishers, New York.

Nicoletti VG, Marino VM, Cuppari C, Licciardello D, et al. (2005). Effect of antioxidant diets on mitochondrial gene expression in rat brain during aging. Neurochem. Res. 30: 737-752.

NRC (1994). Nutrient Requirement of Poultry. 9th edn. Natl. Acad. Press, Washington.

Ojano-Dirain C, Toyomizu M, Wing T, Cooper M, et al. (2007). Gene expression in breast muscle and duodenum from low and high feed efficient broilers. Poult. Sci. 86: 372-381.

Parker N, Affourtit C, Vidal-Puig A and Brand MD (2008). Energization-dependent endogenous activation of proton conductance in skeletal muscle mitochondria. Biochem. J. 412: 131-139.

Rebrin I, Zicker S, Wedekind KJ, Paetau-Robinson I, et al. (2005). Effect of antioxidant-enriched diets on glutathione redox status in tissue homogenates and mitochondria of the senescence-accelerated mouse. Free Radic. Biol. Med. 39: 549-557.

Ronsein GE, Miyamoto S, Bechara E, Di Mascio P, et al. (2006). Oxidação de proteínas por oxigênio singlete: mecanismos de dano, estratégias para detecção e implicações biológicas. Química Nova 29: 563-568.

Rostagno HS, Albino LFT, Donzele JL and Gomes PC (2005). Brazilian Tables for Poultry and Swine: Composition of Feedstuffs and Nutritional Requirements. 2nd edn. Department of Animal Science, Viçosa Federal University, Viçosa.

SAS (2000). User's Guide: Statistics. Statistical Analysis Systems Institute Inc., Cary.

Schauss AC, Huang H, Choi SY, Xu L, et al. (2010). A novel cell-free mitochondrial fusion assay amenable for highthroughput screenings of fusion modulators. BMC Biol. 8: 100.

Scheffler I (1999). Mitochondria. Wiley-Liss Inc., New York.

Tengan CH, Gabbai AA and Moraes CT (1998). Deleções do DNA mitocondrial no envelhecimento: efeito da disfunção na fosforilação oxidativa. Rev. Psiq. Clin. 25: 126-131.

Vidal-Puig AJ (2000). Uncoupling expectations. Nat. Genet. 26: 387-388.

Voge JL, Santiago CA, Aad PY, Goad DW, et al. (2004). Quantification of insulin-like growth factor binding protein mRNA using real-time PCR in bovine granulosa and theca cells: effect of estradiol, insulin, and gonadotropins. Domest. Anim. Endocrinol. 26: 241-258.

Zhang L, Yue HY, Wu SG, Xu L, et al. (2010). Transport stress in broilers. II. Superoxide production, adenosine phosphate concentrations, and mRNA levels of avian uncoupling protein, avian adenine nucleotide translocator, and avian peroxisome proliferator-activated receptor- $\gamma$ coactivator-1 $\alpha$ in skeletal muscles. Poult. Sci. 89: 393-400. 